\title{
No Short-Term Contingency Between Grooming and Food Tolerance in Barbary Macaques (Macaca sylvanus)
}

\author{
Sandra Molesti \& Bonaventura Majolo \\ School of Psychology, University of Lincoln, Lincoln, UK
}

\section{Correspondence}

Sandra Molesti, School of Psychology,

University of Lincoln, Brayford Pool, LN6 7TS

Lincoln, UK.

E-mail: sandra.molesti@outlook.com

Received: September 30, 2014

Initial acceptance: October 29, 2014

Final acceptance: November 9, 2014

(J. Wright)

doi: 10.1111/eth.12346

Keywords: grooming, tolerance, exchange, primate, reciprocity, contingency

\begin{abstract}
The exchange of services such as allo-grooming, allo-preening, food tolerance and agonistic support has been observed in a range of species. Two proximate mechanisms have been proposed to explain the exchanges of services in animals. First, an animal can give a service to a partner depending on how the partner behaved towards it in the recent past. This mechanism is usually tested by examining the within-dyad temporal relation between events given and received over short time periods. Second, the partner choice mechanism assumes that animals give favours towards specific partners but not others, by comparing how each partner behaved towards them over longer time frames. As such, the partner choice mechanism does not make specific predictions on a temporal contingency between services received and given over short time frames. While there is evidence for a long-term positive correlation between services exchanged in animals, results for short-term contingencies between services given and received are mixed. Our study investigated the exchange of grooming for food tolerance in a partially provisioned group of Barbary macaques, by analysing the short-term contingency between these events. Tolerance over food was compared immediately after grooming and in control condition, using food of different shareability. We found no evidence that grooming increases food tolerance or decrease aggression around food in the short term. Food tolerance was affected by the shareability of the food and the sex of the partners. The exchanges of grooming and food tolerance in non-human primates may be little affected by recent single events. We suggest that long-term exchanges between services given and received and social partner choice may play a more important role in explaining social interactions than short-term contingent events.
\end{abstract}

\section{Introduction}

Animals can reciprocate services such as grooming (Schino \& Aureli 2008) and food tolerance (de Kort et al. 2006; Carter \& Wilkinson 2013), but can also exchange these services for different benefits. For example, grooming can be exchanged for agonistic support, access to infant or to mating partners, and for tolerance around food (e.g. Barrett \& Henzi 2001; Watts 2002; Ventura et al. 2006; Emery et al. 2007; Schino 2007; Carne et al. 2011; Fraser \& Bugnyar 2012). Two proximate mechanisms have been proposed to explain the exchanges of services in animals
(Bull \& Rice 1991; Noë 2001; Tiddi et al. 2011). The first mechanism (i.e. 'temporal relation between events'; Tiddi et al. 2011) describes within-dyad exchanges of services as based on a short-term contingency between what an animal gives and receives from a given social partner (Schino et al. 2009; Cheney et al. 2010). The second mechanism (i.e. 'partner choice'; Tiddi et al. 2011) assumes that animals preferentially exchange services with some social partners but not others, based on their history of social interactions (Noë 2001; Silk 2002, 2003; Schino \& Aureli $2009,2010)$. Therefore, individuals would exchange services more often with social partners from whom 
they received more, even if no temporal contingency is found between services received and given over short time frames.

While the partner choice mechanism seems to explain the exchange of services in social animals (Schino 2007; Schino \& Aureli 2009), the role of the 'temporal relation between events' mechanism remains unclear. For example, a number of studies have tested the long-term exchange of grooming for food tolerance, showing that grooming is positively related to higher tolerance level in a variety of nonhuman primates (Pastor-Nieto 2001; Mitani 2006; Ventura et al. 2006; Carne et al. 2011; Tiddi et al. 2011), but also in other animals such as birds (e.g. de Kort et al. 2006; Emery et al. 2007). Conversely, support for a short-term contingency between grooming given and food tolerance received is mixed. In wild tufted capuchin monkeys (Cebus apella), Tiddi et al. (2011) found no evidence that food tolerance increased after grooming received. In captive chimpanzees (Pan troglodytes), food tolerance under experimental conditions increased in the $2 \mathrm{~h}$ following grooming, in the recipient but not the donor of grooming (de Waal 1989, 1997). Moreover, the effect of grooming on food tolerance was stronger for dyads of individuals who rarely groomed each other (de Waal 1997). However, in both chimpanzees and bonobos (Pan paniscus), the short-term positive effect of grooming received on food tolerance disappeared when controlling for social factors such as the strength of social bonds, sex and dominance rank, suggesting that food tolerance was dependent on other factors than being strongly related to the contingency of recent single events (Jaeggi et al. 2013).

The scarcity of studies that have tested the 'temporal relation between events' mechanism makes it difficult to conclude whether this mechanism does not explain the exchange of services in animals or whether its occurrence depends on the value and amount of resources at stake. The aim of our study was to analyse the short-term contingency of grooming on food tolerance using food tests in a partially provisioned group of wild Barbary macaques. We defined food tolerance, within a given dyad, as the lower-ranking individual feeding while being within $1.5 \mathrm{~m}$ proximity of the higher-ranking monkey. We first assessed whether food tolerance between two monkeys was higher immediately after they exchanged grooming than when they had not groomed each other, and whether the direction of grooming affected tolerance (i.e. whether the groomer or groomee was more likely to be tolerated near food). Second, we predicted that grooming would decrease post-grooming aggressive response around food from the dominant individual of the grooming dyad towards the subordinate animal, facilitating contingent exchanges (de Waal 1997; Jaeggi et al. 2013). Therefore, we analysed whether aggression around food resources between two monkeys was lower immediately after they exchanged grooming than when they had not groomed each other, and whether the direction of grooming affected aggression. Finally, food tolerance may depend on the type of food available, that is, on whether the resource is shareable or not (Elgar 1986; Stevens 2004). For example, in rhesus macaques (Macaca mulatta), the larger the food items the more aggression was displayed, and the level of food dispersion affected the ability of monkeys to monopolize food (Mathy \& Isbell 2001; see also Hauser et al. 1993). Consequently, we also analysed whether the shareability of the food resource affected food tolerance and aggression.

\section{Methods}

\section{Study Subjects}

Subjects of this study were 24 adult ( $\geq 6$ yr old) and subadult (i.e. 4-5 yr old) monkeys (nine adult males, 10 adult females, two subadult males and three subadult females) of a group living in the Middle Atlas Mountains of Morocco $\left(33^{\circ} 24^{\prime} \mathrm{N}-005^{\circ} 12^{\prime} \mathrm{W}\right)$. The group lived in a deciduous cedar and oak forest within the Ifrane National Park, between 1600 and $1860 \mathrm{~m}$ a.s.l. The study group was chosen because it was partially provisioned by tourists and local people (Maréchal et al. 2011). The animals in our study group were often near a road cutting through their home range and could be approached by tourists up to around $1 \mathrm{~m}$ distance. Tourists were particularly abundant in the middle hours of the day and fed the monkeys with a variety of food, such as fruits, bread and peanuts. Such level of provisioning allowed us to run food tests with the monkeys without affecting their usual diet and behaviour. Permission to conduct this study was granted by the Haut Commissariat aux Eaux et Forêts et à la Lutte Contre la Désertification of Morocco and the Ethics Committee of the University of Lincoln, UK.

\section{Data Collection}

We ran a series of food tests between June 2011 and January 2012. To assess whether tolerance over food within a given dyad, from the higher-ranking monkey of the dyad towards the lower-ranking monkey, 
increased after grooming, we conducted food tests in two different conditions: immediately following (i.e. within 5 s) a grooming interaction and in control conditions where two monkeys were in proximity (i.e. $\leq 1.5 \mathrm{~m}$ ) but not exchanging grooming. We collected food tests opportunistically after grooming interactions observed from start to end. To avoid over-representation of some animals/dyads, we gave priority to animals/dyads for which we had the least number of tests if more than one dyad was grooming at the same time. As soon as a grooming interaction started, we recorded the ID of the monkeys, their role (i.e. groomer or groomee), sex, and dominance rank, as well as the duration of the grooming and whether the partners switched their groomer/groomee role during the grooming interaction. We conducted food tests on the two grooming partners (we discarded grooming interactions involving three animals or more) as soon as the grooming interaction stopped (i.e. the monkeys were not observed grooming for $5 \mathrm{~s}$ ). If one or both monkeys left immediately after the grooming ended, no food test was conducted. As soon as grooming was over, we placed a food reward on the ground at equal distance to the two monkeys, $1 \mathrm{~m}$ in front of them. For each test, we recorded the ID of the monkey who got the food reward as well as the occurrence of any aggressive interaction between the two individuals (i.e. lunge, charge, chase, grab, open mouth and stare). For each food test, data collection was stopped when all the food was eaten (an aggressive behaviour occurring within $5 \mathrm{~s}$ of the consumption of the last item of food was still recorded) or when the monkeys moved away from the food for more than $1.5 \mathrm{~m}$.

As control conditions, we conducted food tests on two monkeys being in proximity for a minimum of $10 \mathrm{~s}$ (i.e. within $1.5 \mathrm{~m}$ ) but not exchanging grooming. The tests were postponed if the monkeys had been observed grooming in the $10 \mathrm{~min}$ prior to the test. The same data collection procedure was followed for both conditions.

We used two food tolerance conditions for the tests. The first condition, defined as 'non-shareable', consisted of food that could be grabbed and eaten by only one monkey. For the non-shareable condition, we used one food item (around $2.5 \times 1.5 \mathrm{~cm}$ ) which was either a piece of fruit (i.e. orange, apple or mandarin), vegetable (i.e. carrot, courgette or tomato), bread or peanut in shell. The second food-sharing condition, defined as 'shareable', consisted of food that could be eaten simultaneously by two monkeys being in proximity (i.e. within $1.5 \mathrm{~m}$ ). For this condition, we dispersed a handful of wheat (i.e. around $25 \mathrm{~g}$ ) on the ground, within an area of $50 \mathrm{~cm}$ of diameter to potentially allow two individuals to eat in proximity at the same time. Prior to the data collection, we ran a series of pilot tests to determine whether the study monkeys would eat the food used for the non-shareable and shareable conditions. These pilot tests showed that fruit, vegetable, bread, peanut and wheat were eaten at a similar pace by all the study subjects.

We ran each test using only one of the two conditions; the shareable and non-shareable food conditions were balanced across tests. For each test, we also recorded the time of the day to control for satiety effects on tolerance over food (Perry \& Rose 1994; Hattori et al. 2012). The time of the day was divided in three categories, each lasting $4 \mathrm{~h}$ : 'morning' (i.e. tests conducted from 6 am to $10 \mathrm{am}$ ), 'noon' (i.e. tests conducted from 10 am to $2 \mathrm{pm}$ ) and 'afternoon' (i.e. tests conducted from $2 \mathrm{pm}$ to $6 \mathrm{pm})$.

We collected scan samples (Altmann 1974) every hour on the activity of all visible monkeys to assess the strength of the social bonds between the study animals. For each visible monkey, we recorded their proximity (i.e. $\leq 1.5 \mathrm{~m}$ but not grooming), or grooming with other adults or subadults in the group, as well as the identity of their social partner. We used ad libitum data (Altmann 1974) to determine the dominance hierarchy of the study animals. Ad libitum data were collected opportunistically on any observed dyadic conflicts not involving third parties and with a clear-cut result (i.e. one opponent displayed aggressive behaviour and the other opponent displayed submissive behaviour; that is make room, give ground, flee and present submission).

\section{Data Analysis}

We calculated a composite sociality index (CSI) to measure the strength of social bonds between two individuals, based on the data collected during 929 hourly scans. For each dyad of monkeys, we calculated their CSI based on the formula (Sapolsky et al. 1997; Silk et al. 2003):

$$
\frac{\sum_{i=1}^{2} \frac{x_{i}}{m_{i}}}{2}
$$

$\mathrm{x}_{\mathrm{i}}=$ dyad's value for each of the two behavioural measures (i.e. the proportion of hourly scans in which two monkeys of a dyad were grooming, or in proximity, divided by the total number of scans in which the activity of the two animals was recorded).

$\mathrm{m}_{\mathrm{i}}=$ group's median value for the proportion of hourly scans spent grooming, or in proximity, by the whole group.

A high CSI indicates a strong social bond between two monkeys of a dyad. The CSI values ranged from 0 
to 12.4 (mean CSI value $\pm \mathrm{SE}=1.7 \pm 0.1$ ). The CSI is a reliable index to measure social bonds using intercorrelated variables in various primates, including in Barbary macaques (e.g. Molesti \& Majolo 2013).

Based on the dyadic conflicts collected ad libitum, we constructed a winner-loser socio-metric dominance matrix. We used MATMAN 1.1 (de Vries et al. 1993; Noldus Information Technology 2003) to assign an ordinal dominance rank to each study monkey. All males were dominant over females.

Among the 386 tests used for the analyses, 189 were post-grooming sessions (97 with non-shareable food and 92 with shareable food), and 197 were control sessions (95 with non-shareable food and 102 with shareable food). Among these tests, 29 were conducted after grooming interactions where the partners switched their groomer/groomee role at least once (17 with non-shareable food and 12 with shareable food). The mean \pm SE number of tests per monkey was $15.8 \pm 2.2(\mathrm{n}=24)$ for the post-grooming condition and $16.4 \pm 1.6(n=24)$ for the control condition. The duration of the grooming bouts ranged between $32 \mathrm{~s}$ and $2115 \mathrm{~s}$ (mean $\pm \mathrm{SE}=342.2 \pm 28.8)$.

We ran a series of generalized linear mixed models (GLMMs) with a logistic distribution, using STATA v12.1 software (StataCorp 2011). For each GLMM, each food test was treated as a single data point and we entered the ID of the two focal monkeys as two crossed random factors (Pinheiro \& Bates 2000). For each model, we also included the CSI values of the dyad and their sex (categorical variable: different-sex or same-sex pairs) to assess whether tolerance was higher and aggression lower in dyads having stronger social bonds, and whether the sex of the partners affected food tolerance and aggression (e.g. de Waal 1997; Gilby 2006; Lehmann \& Boesch 2008; van Noordwijk \& van Schaik 2009; Tiddi et al. 2011; Jaeggi et al. 2013). Given that all females were lower ranking than males, the occurrence of aggression and tolerance within different-sex dyads $(\mathrm{N}=276)$ analysed males tolerance towards females. We decided to combine together female-female and male-male dyads into the 'same-sex' category as the number of tests on male-male dyads was very small $(\mathrm{N}=10)$ compared with tests on female-female dyads $(\mathrm{N}=100)$. Such a difference in sample size was due to the fact that males were less frequently engaged in grooming or proximity with same-sex partners compared to females. We also entered in the models the difference of dominance status between partners, the time of the day, and the duration of the grooming interaction to control for their potential effect on tolerance and aggression over food. When appropriate, a control variable indicating whether the partners switched their role during grooming was also entered as the occurrence of grooming turn taking may influence the tolerance over food of grooming partners and aggression. For the sake of brevity, results of control variables are not discussed here.

\section{Tolerance}

We ran two GLMMs with a logistic distribution to assess whether tolerance occurred more often after grooming than in control condition. We ran the first GLMM on all the data set, and we included in the second GLMM only controls and post-grooming sessions where a subordinate monkey groomed a dominant monkey (and so excluding also post-grooming sessions where the partners switched their groomer/ groomee role). For the two GLMMs, the binary dependent variable was whether tolerance occurred or not. We entered in the models as predicting variables the testing condition (i.e. post-grooming or control), the shareability of food (i.e. whether the food was non-shareable or shareable) and the interaction between these two variables.

We ran one GLMM with a logistic distribution to assess whether lower-ranking monkey received more tolerance after grooming when they were the groomer than the groomee. We ran this GLMM only on post-grooming data, excluding tests where the grooming partners switched their groomer/groomee role. The binary dependent variable was whether tolerance occurred after grooming or not. The categorical test variables were the role of the partners during grooming (i.e. groomer or groomee), the shareability of food and the interaction between these two variables.

\section{Aggression}

We ran two GLMMs with a logistic distribution to assess whether aggression around food occurred less often after grooming than in control condition. We ran the first GLMM on all the data whereas we included in the second GLMM only controls and postgrooming sessions where a subordinate monkey groomed a dominant monkey (and so excluding also post-grooming sessions where the partners switched their groomer/groomee role). For the two GLMMs, the binary dependent variable was whether aggression occurred or not. The predicting variables were the testing condition, the shareability of food and the interaction between these two variables.

We ran one GLMM with a logistic distribution to assess whether lower-ranking monkey received less 
aggression after grooming when they were the groomer than the groomee. We only ran this analysis on post-grooming data and excluding tests where the grooming partners switched their groomer/groomee role. The binary dependent variable was whether aggression occurred in post-grooming sessions or not. The categorical predicting variables were the role of the partners during grooming, the shareability of food and the interaction between these two variables.

\section{Results}

\section{Tolerance}

When analysing all the data set, exchanging grooming before the food test did not improve food tolerance from dominant to subordinate (Table 1; Fig. 1). Food tolerance was higher for shareable than non-shareable food (Table 1; Fig. 1). There was no significant effect of the interaction between testing conditions (i.e. post-grooming vs control conditions) and shareability of food on tolerance (Table 1). There was a non-significant tendency showing a higher level of tolerance between dyads of higher CSI values (Table 1). Tolerance was significantly higher for different-sex than same-sex dyads, so males tolerated females around food more than the level of tolerance observed within same-sex dyads (Table 1). Similar results were found when focusing on data where a subordinate monkey groomed a dominant monkey (see supporting information).

The lower-ranking monkeys did not obtain the reward after grooming more often when they were the groomer than the groomee (Table 2). Post-grooming tolerance was higher for shareable than nonshareable food (Table 2). There was no effect of the

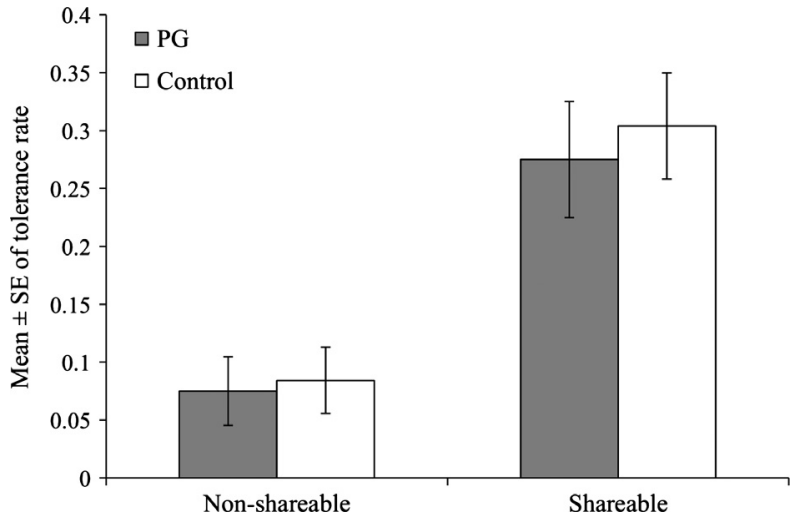

Fig. 1: Mean $\pm S E$ of tolerance rate in post-grooming $(P G)$ and control conditions, for non-shareable and shareable food, including all data.

interaction between the role of the lower-ranking monkey and shareability of food (Table 2). Tolerance was not affected by the CSI values of the dyads, but was higher for different-sex dyads compared to samesex dyads (Table 2).

\section{Aggression}

All aggressive behaviours were directed from dominant to subordinate monkeys. When analysing the whole data set, previous grooming did not affect aggression received by subordinates, and this occurred regardless of the shareability of food (Table 3; Fig. 2). There was no significant effect of the interaction between testing conditions and shareability of food on aggression (Table 3). The CSI values had no significant effect on aggression, but aggression was significantly lower for different-sex dyads than dyads of same sex (Table 3 ). Therefore, males were less aggressive towards females around food than same-sex

Table 1: Odds ratio and significance of the test and control variables entered in the GLMM to compare tolerance between post-grooming and control conditions for all data $(n=386)$

\begin{tabular}{|c|c|c|c|c|}
\hline Variables & Odds ratio $\pm S E$ & z & $p$ & $95 \% \mathrm{Cls}$ \\
\hline Testing condition & $1.16 \pm 0.7$ & 0.25 & 0.8 & $0.36-3.8$ \\
\hline Shareability & $6.11 \pm 2.95$ & 3.75 & 0.001 & $2.37-15.73$ \\
\hline Testing condition * Shareability & $0.81 \pm 0.52$ & -0.32 & 0.75 & $0.23-2.87$ \\
\hline CSI of the dyad & $1.1 \pm 0.05$ & 1.91 & 0.056 & $1-1.21$ \\
\hline Sex of the dyad & $0.31 \pm 0.13$ & -2.89 & 0.004 & $0.14-0.69$ \\
\hline \multicolumn{5}{|l|}{ Time of the day } \\
\hline Morning vs. Noon & $1.65 \pm 0.57$ & 1.45 & 0.15 & $0.84-3.25$ \\
\hline Morning vs. Afternoon & $1.53 \pm 0.55$ & 1.19 & 0.24 & $0.76-3.1$ \\
\hline Noon vs. Afternoon & $0.93 \pm 0.33$ & -0.21 & 0.83 & $0.46-1.86$ \\
\hline Role reverse & $0.5 \pm 0.34$ & -1.02 & 0.31 & $0.13-1.89$ \\
\hline Grooming duration & $1 \pm 0.001$ & 0.61 & 0.54 & $1-1.001$ \\
\hline
\end{tabular}


Table 2: Odds ratio and significance of the test and control variables entered in the GLMM to compare post-grooming tolerance between when the lower-ranking was the groomer or the groomee $(n=160)$

\begin{tabular}{lcccc}
\hline Variables & Odds ratio \pm SE & z & $p$ & $95 \%$ Cls \\
\hline Grooming role & $6.36 \pm 8.62$ & 1.36 & 0.17 & $0.45-90.63$ \\
Shareability & $13.15 \pm 11.73$ & 2.89 & 0.004 & $2.29-75.56$ \\
Grooming role * Shareability & $0.26 \pm 0.29$ & -1.2 & 0.23 & $0.03-2.37$ \\
CSI of the dyad & $1.1 \pm 0.08$ & 1.21 & 0.23 & $0.95-1.27$ \\
Sex of the dyad & $0.27 \pm 0.15$ & -2.35 & 0.02 & $0.09-0.8$ \\
Dominance status & $1.04 \pm 0.05$ & 0.77 & 0.44 & $0.95-1.13$ \\
Time of the day & & & 0.92 \\
$\quad$ Morning vs. Noon & $0.94 \pm 0.53$ & -0.11 & 0.8 & $0.31-2.85$ \\
$\quad$ Morning vs. Afternoon & $0.85 \pm 0.54$ & -0.25 & 0.88 & $0.25-2.93$ \\
$\quad$ Noon vs. Afternoon & $0.9 \pm 0.61$ & -0.15 & 0.96 & $0.24-3.43$ \\
Grooming duration & $1 \pm 0.001$ & -0.06 & $1-1.001$ \\
\hline
\end{tabular}

Table 3: Odds ratio and significance of the test and control variables entered in the GLMM to compare aggression between post-grooming and control conditions for all data $(\mathrm{n}=386)$

\begin{tabular}{lcccc}
\hline Variables & Odds ratio \pm SE & z & $p$ & $95 \%$ Cls \\
\hline Testing condition & $2.07 \pm 1.31$ & 1.15 & 0.25 & $0.6-7.13$ \\
Shareability & $1.25 \pm 0.66$ & 0.42 & 0.67 & $0.44-3.54$ \\
Testing condition * Shareability & $2.59 \pm 1.83$ & 1.35 & 0.18 & $0.65-10.32$ \\
CSI of the dyad & $1.03 \pm 0.06$ & 0.5 & 0.62 & $0.92-1.15$ \\
Sex of the dyad & $3.73 \pm 1.48$ & 3.33 & 0.001 & $1.72-8.12$ \\
Dominance status & $1 \pm 0.02$ & -0.41 & 0.69 & $0.96-1.03$ \\
Time of the day & $1.36 \pm 0.52$ & 0.81 & 0.42 & $0.65-2.87$ \\
$\quad$ Morning vs. Noon & $0.9 \pm 0.39$ & -0.23 & 0.82 & $0.38-2.13$ \\
$\quad$ Morning vs. Afternoon & $0.66 \pm 0.28$ & -0.96 & 0.34 & $0.29-1.53$ \\
$\quad$ Noon vs. Afternoon & $2.21 \pm 1.55$ & 1.12 & 0.26 & $0.56-8.77$ \\
Role reverse & $1 \pm 0.001$ & -0.25 & 0.8 & $1-1.001$ \\
Grooming duration & & & \\
\hline
\end{tabular}

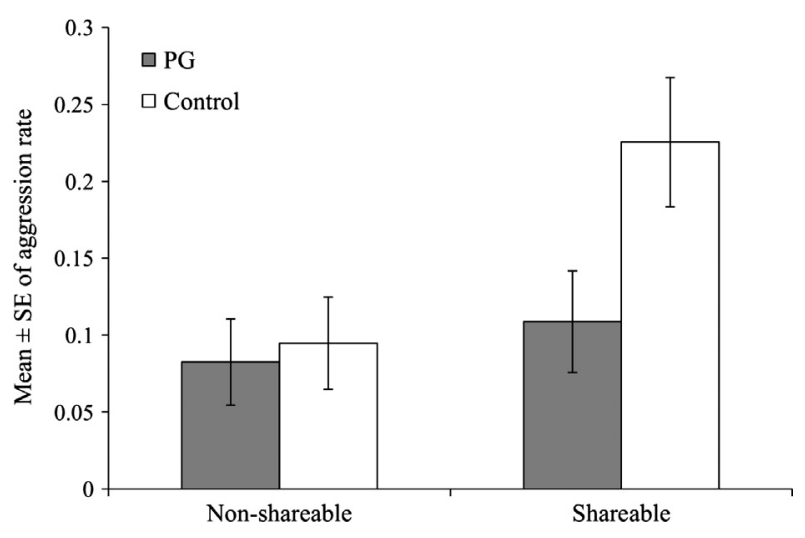

Fig. 2: Mean $\pm \mathrm{SE}$ of aggression rate in post-grooming (PG) and control conditions, for non-shareable and shareable food, including all data.

dyads. Similar results were found when focusing on data where a subordinate monkey groomed a dominant monkey (see supporting information).

The lower-ranking monkeys did not receive less aggression after grooming when they were the groomer than the groomee (Table 4). Post-grooming aggression was not significantly different between shareable and non-shareable food (Table 4). There was no significant effect of the interaction between the role of the lower-ranking monkey and shareability of food on post-grooming aggression (Table 4). Aggression was not affected by the CSI values of the dyads (Table 4). There was a marginally non-significant relationship showing lower aggression rate for different-sex dyads than same-sex dyads (Table 4).

\section{Discussion}

The results of this study show no evidence of a shortterm contingency between grooming and food tolerance in Barbary macaques, even when the role of the grooming partners (i.e. groomer/groomee) was taken into account in the analyses. As predicted, food tolerance was higher for shareable than for non-shareable food. Our results are consistent with recent studies showing a lack of short-term contingency between 
Table 4: Odds ratio and significance of the test and control variables entered in the GLMM to compare post-grooming aggression between when the lower-ranking was the groomer or the groomee $(n=160)$

\begin{tabular}{|c|c|c|c|c|}
\hline Variables & Odds ratio $\pm S E$ & z & $p$ & $95 \% \mathrm{Cls}$ \\
\hline Grooming role & $0.52 \pm 0.71$ & -0.48 & 0.63 & $0.04-7.61$ \\
\hline Shareability & $1.2 \pm 1.1$ & 0.2 & 0.84 & $0.21-6.87$ \\
\hline Grooming role * Shareability & $1.29 \pm 1.7$ & 0.2 & 0.85 & $0.1-16.71$ \\
\hline CSI of the dyad & $0.99 \pm 0.1$ & -0.14 & 0.89 & $0.8-1.21$ \\
\hline Sex of the dyad & $4.24 \pm 3.31$ & 1.85 & 0.06 & $0.92-19.62$ \\
\hline \multicolumn{5}{|l|}{ Time of the day } \\
\hline Morning vs. Noon & $1.41 \pm 0.92$ & 0.52 & 0.6 & $0.39-5.06$ \\
\hline Morning vs. Afternoon & $0.4 \pm 0.47$ & -0.78 & 0.44 & $0.04-4.03$ \\
\hline Noon vs. Afternoon & $0.28 \pm 0.33$ & -1.08 & 0.28 & $0.03-2.79$ \\
\hline Grooming duration & $1 \pm 0.001$ & -0.86 & 0.39 & $1-1.001$ \\
\hline
\end{tabular}

grooming and tolerance over food in capuchin monkeys (Tiddi et al. 2011) and chimpanzees (Jaeggi et al. 2013; but see de Waal 1989, 1997).

The absence of short-term contingency between services given and received has also been found for the exchange of other services such as between food tolerance and mating opportunities (e.g. Gilby et al. 2010), and between reciprocity of food provision in experimental setups in chimpanzees (Melis et al. 2008; Brosnan et al. 2009; Yamamoto \& Tanaka 2009), capuchin monkeys (Pelé et al. 2010) and Tonkean macaques (Macaca tonkeana; Pelé et al. 2010). A recent study showed also no short-term reciprocation of food exchanges in an experimental set-up in chimpanzees, bonobos, gorillas (Gorilla gorilla), orangutans (Pongo abelii), brown capuchin monkeys and spider monkeys (Ateles geoffroyi; Amici et al. 2014).

While no contingency has been found between grooming and food tolerance in our study, a positive relation between overall grooming received and food tolerance was found in captive Barbary macaques (Carne et al. 2011). Under the partner choice model, short-term contingencies are expected to be negligible if exchanges are affected by long-term relationship properties (Schino \& Aureli 2009, 2010). Thus, individuals would preferentially interact with partners from whom they have received the most services in the past over long time periods, regardless of the most recent interactions (Schino \& Aureli 2009, 2010). There is evidence that exchanges become more balanced over time in non-human primates (Schino et al. 2007, 2009; Gomes et al. 2009; Schino \& Pellegrini 2009; Jaeggi et al. 2010, 2013; Tiddi et al. 2011). For example, in a recent experiment of food tolerance in capuchin monkeys, individuals preferred to reciprocate food tolerance according to long-term social bonds rather than according to recent food tolerance events (Sabbatini et al. 2012). Furthermore in Barbary macaques, females reciprocate grooming and interchange grooming for agonistic support and tolerance while feeding over long-time period (Carne et al. 2011). In male Barbary macaques, social affiliations such as close proximity and grooming during the non-mating season predict coalition formations during the mating season (Berghänel et al. 2011). Services may thus be exchanged according to long-term social interactions while single recent events may be negligible in Barbary macaques.

Long-term exchanges could be mediated by social bonds, that is, individuals would make their decision about which partner to cooperate with based on the emotional states associated with each potential partner (Schino \& Aureli 2009). This mechanism obviates the need for scorekeeping and would thus not require high cognitively demanding abilities (Silk 2002; Schino \& Aureli 2009, 2010; de Waal \& Suchak 2010). Therefore, short-term contingencies may play a more important role in exchanges between individuals who rarely interact with each other (e.g. de Waal 1997; Roberts \& Sherratt 1998; Jaeggi et al. 2013; Tan \& Hare 2013). Furthermore, the emotional mediation of reciprocity may facilitate the long-term exchanges of services of different nature (Schino \& Aureli 2009). Indeed, in the long-term, the receipt of various services such as grooming, food tolerance and agonistic support may have similar emotional consequences in promoting the social bonds between individuals and thus the overall exchanges of services between them (Schino \& Aureli 2009). While there was a tendency showing a higher level of tolerance between dyads of higher CSI values, this effect was not significant. However, note that we calculated a CSI index per dyad without taking into account how much each 
member of the dyad contributes to the social bond. Tolerance may depend on the relative dominance rank of the two members of a dyad as well as their contribution to the social relationship. Therefore, one would need to compare tolerance in dyads composed of animals contributing differently to the relationship versus those where the two animals contribute about equally, while controlling for their dominance rank and vice versa. Our data set did not allow us to run these analyses. Consequently, we could not assess whether individuals directed more tolerance towards individuals from whom they received more grooming in the long term (e.g. Carne et al. 2011). It is also possible that food tests are perceived as more competitive for animals than more naturally occurring feeding (Wobber et al. 2010; Jaeggi et al. 2013), especially if the food reward used is highly desirable, hindering food tolerance.

Aggression around food was not affected by whether a grooming interaction occurred or not before a food test. The modulating effect of grooming on aggression is still debated. In some studies, aggression was found to decrease in the aftermath of grooming (Silk 1982; Gumert \& Ho 2008; Aureli \& Yates $2010)$, and the probability for the monkeys to stay in proximity to increase (Troisi et al. 1989; Gumert \& Ho 2008; Aureli \& Yates 2010). However, other studies did not find similar results (e.g. Perry 1996; Schino et al. 2005; Ventura et al. 2006). For example, in chimpanzees and bonobos, there was no evidence that aggressive behaviours during food requests decreased when grooming occurred before feeding (Jaeggi et al. 2013). In our study, the rate of aggression remained low across post-grooming and control conditions.

This study highlights two main factors that may affect food tolerance in non-human primates. First, tolerance was higher for shareable than non-shareable food. When food resources can potentially be shared with other group members, the costs associated with sharing, such as a reduced food intake, may decrease, increasing the probability of food tolerance, even when food resources can be monopolisable (Kavanagh 1972; Slocombe \& Newton-Fisher 2005; Jaeggi \& van Schaik 2011). The size, quality, availability and defendability of food resources affect food tolerance in animals (e.g. Elgar 1986; Boccia et al. 1988; White \& Wrangham 1988; Goldberg et al. 2001; Mathy \& Isbell 2001; Johnson et al. 2004; Melis et al. 2006). Although the increase of tolerance for shareable food was not accompanied by a decrease of aggression, aggression rate remained low. We cannot completely rule-out the possibility that differences of tolerance between shareable and non-shareable conditions were due to different preference for the food types used in the two conditions. However, food preference is unlikely to explain our results. Pilot tests showed that the monkeys ate all the types of food about equally. Moreover, each study animal was tested using different food types and this should, at least partially, control for individual food preference when comparing broad categories of shareable versus non-shareable food.

A second factor that affects food tolerance is the sex of the animals: tolerance was higher and aggression lower from males towards females than for dyads composed of animals of the same sex. A positive relation exists between food tolerance and mating success in non-human primates (e.g. Tutin 1979; Gomes \& Boesch 2009; van Noordwijk \& van Schaik 2009; Jaeggi \& van Schaik 2011; Dubuc et al. 2012). In a recent analyses conducted on 68 non-human primate species, Jaeggi \& van Schaik (2011) revealed that male-female food tolerance co-evolved with the opportunities for female mate choice, that is, food possessors share with potential group mates who could provide or withhold mating opportunities. This may be also the case in Barbary macaques, where groups are multimale-multifemale and females mate with several males, giving opportunities for female mate choice (Heistermann et al. 2006).

In conclusion, Barbary macaques did not show a short-term contingency between grooming and food tolerance. This study supports the hypothesis that the exchange of services is better explained by partner choice mechanisms than by short-term contingency of services given and received (Schino \& Aureli 2009, 2010; Jaeggi et al. 2013).

\section{Acknowledgements}

We would like to thank the Haut Commissariat aux Eaux et Forêts et à la Lutte Contre la Désertification of Morocco for permission to conduct the research, and Professor Mohamed Qarro (Ecole Nationale Forestière d'Ingénieurs, Morocco) for his support. We are grateful to Neal Marquez, Barbora Kuběnová and Laura Martínez Íñigo for assistance in the field.

\section{Literature Cited}

Altmann, J. 1974: Observational study of behavior: sampling methods. Behaviour 49, 227-267.

Amici, F., Aureli, F., Mundry, R., Amaro, A. S., Barroso, A. M., Ferretti, J. \& Call, J. 2014: Calculated reciprocity? A 
comparative test with six primate species. Primates 55, $447-457$.

Aureli, F. \& Yates, K. 2010: Distress prevention by grooming others in crested black macaques. Biol. Lett. 3, 231 $-233$.

Barrett, L. \& Henzi, S. P. 2001: The utility of grooming in baboon troops. In: Economics in Nature: Social Dilemmas, Mate Choice and Biological Markets. (Nö̈, R., van Hooff, J. A. R. A. M., Hammerstein, P., eds). Cambridge University Press, Cambridge, pp. 119-145.

Berghänel, A., Ostner, J., Schröder, U. \& Schülke, O. 2011 : Social bonds predict future cooperation in male Barbary macaques, Macaca sylvanus. Anim. Behav. 81, 11091116.

Boccia, M. L., Laudenslager, M. \& Reite, M. 1988: Food distribution, dominance, and aggressive behaviors in bonnet macaques. Am. J. Primatol. 16, 123-130.

Brosnan, S., Silk, J., Henrich, J., Mareno, M., Lambeth, S. S Schapiro, S. 2009: Chimpanzees (Pan troglodytes) do not develop contingent reciprocity in an experimental task. Anim. Cogn. 12, 587-597.

Bull, J. J. \& Rice, W. R. 1991: Distinguishing mechanisms for the evolution of co-operation. J. Theor. Biol. 149, 63 -74 .

Carne, C., Wiper, S. \& Semple, S. 2011: Reciprocation and interchange of grooming, agonistic support, feeding tolerance, and aggression in semi-free-ranging Barbary macaques. Am. J. Primatol. 73, 1127-1133.

Carter, G. \& Wilkinson, G. 2013: Food sharing in vampire bats: reciprocal help predicts donations more than relatedness or harassment. Proc. R. Soc. Lond. B 280, 1753.

Cheney, D. L., Moscovice, L. R., Heesen, M., Mundry, R. \& Seyfarth, R. M. 2010: Contingent cooperation between wild female baboons. Proc. Natl Acad. Sci. USA 107, 9562-9566.

Dubuc, C., Hughes, K. D., Cascio, J. \& Santos, L. R. 2012: Social tolerance in a despotic primate: co-feeding between consortship partners in rhesus macaques. Am. J. Phys. Anthropol. 148, 73-80.

Elgar, M. A. 1986: House sparrows establish foraging flocks by giving chirrup calls if the resources are divisible. Anim. Behav. 34, 169-174.

Emery, N. J., Seed, A. M., von Bayern, A. M. P. \& Clayton, N. S. 2007: Cognitive adaptations of social bonding in birds. Philos. Trans. R. Soc. Lond., B, Biol. Sci. 362, 489 -505 .

Fraser, O. N. \& Bugnyar, T. 2012: Reciprocity of agonistic support in ravens. Anim. Behav. 83, 171-177.

Gilby, I. C. 2006: Meat sharing among the Gombe chimpanzees: harassment and reciprocal exchange. Anim. Behav. 71, 953-963.

Gilby, I. C., Thompson, M. E., Ruane, J. D. \& Wrangham, R. W. 2010: No evidence of short-term exchange of meat for sex among chimpanzees. J. Hum. Evol. 59, 44 -53 .
Goldberg, J. L., Grant, J. W. A. \& Lefebvre, L. 2001: Effects of the temporal predictability and spatial clumping of food on the intensity of competitive aggression in the Zenaida dove. Behav. Ecol. 12, 490—495.

Gomes, C. M. \& Boesch, C. 2009: Wild chimpanzees exchange meat for sex on a long-term basis. PLoS ONE 4, e5116.

Gomes, C. M., Mundry, R. \& Boesch, C. 2009: Long-term reciprocation of grooming in wild West African chimpanzees. Proc. R. Soc. Lond. B 276, 699-706.

Gumert, M. D. \& Ho, M. H. 2008: The trade balance of grooming and its coordination of reciprocation and tolerance in Indonesian long-tailed macaques (Macaca fascicularis). Primates 49, 176-185.

Hattori, Y., Leimgruber, K., Fujita, K. \& de Waal, F. B. M. 2012: Food-related tolerance in capuchin monkeys (Cebus apella) varies with knowledge of the partner's previous food-consumption. Behaviour 149, 171185.

Hauser, M. D., Teixidor, P., Fields, L. \& Flaherty, R. 1993: Food-elicited calls in chimpanzees: effects of food quantity and divisibility. Anim. Behav. 45, 817-819.

Heistermann, M., Möhle, U., Wallner, B., Dittami, J., Shaw, E. \& Hodges, K. 2006: Reproductive cycle and mating patterns in female Barbary macaques. In: The Barbary Macaque: Biology, Management and Conservation. (Hodges, J. K., Cortes, J., eds). Nottingham University Press, Nottingham, pp. 95-107.

Jaeggi, A. V. \& van Schaik, C. P. 2011: The evolution of food sharing in primates. Behav. Ecol. Sociobiol. 65, 2125-2140.

Jaeggi, A. V., Burkart, J. M. \& van Schaik, C. P. 2010: On the psychology of cooperation in humans and other primates: combining the natural history and experimental evidence of prosociality. Philos. Trans. R. Soc. Lond., B, Biol. Sci. 365, 2723-2735.

Jaeggi, A. V., De Groot, E., Stevens, J. M. G. \& van Schaik, C. P. 2013: Mechanisms of reciprocity in primates: testing for short-term contingency of grooming and food sharing in bonobos and chimpanzees. Evol. Hum. Behav. 34, 69-77.

Johnson, C. A., Grant, J. W. A. \& Giraldeau, L.-A. 2004: The effect of patch size and competitor number on aggression among foraging house sparrows. Behav. Ecol. 15, 412-418.

Kavanagh, M. 1972: Food-sharing behavior within a group of douc monkeys (Pygathrix nemaeus nemaeus). Nature 239, 406-407.

de Kort, S. R., Emery, N. J. \& Clayton, N. S. 2006: Food sharing in jackdaws, Corvus monedula: what, why and with whom? Anim. Behav. 72, 297-304.

Lehmann, J. \& Boesch, C. 2008: Sex differences in chimpanzee sociality. Am. J. Primatol. 29, 65-81.

Maréchal, L., Semple, S., Majolo, B., Qarro, M. \& MacLarnon, A. 2011: Impacts of tourism on anxiety and physi- 
ological stress in wild male Barbary macaques. Biol. Conserv. 144, 2188-2193.

Mathy, J. W. \& Isbell, L. A. 2001: The relative importance of size of food and interfood distance in eliciting aggression in captive rhesus macaques (Macaca mulatta). Folia Primatol. 72, 268-277.

Melis, A. P., Hare, B. \& Tomasello, M. 2006: Engineering cooperation in chimpanzees: tolerance constraints on cooperation. Anim. Behav. 72, 275-286.

Melis, A. P., Hare, B. \& Tomasello, M. 2008: Do chimpanzees reciprocate received favours? Anim. Behav. 76, $951-962$.

Mitani, J. C. 2006: Reciprocal exchange in chimpanzees and other primates. In: Cooperation in Primates and Humans: Mechanisms and Evolution. (van Schaik, C. P., Kappeler, P. M., eds). Springer, New-York, pp. $101-$ 113.

Molesti, S. \& Majolo, B. 2013: Grooming increases selfdirected behaviour in wild Barbary macaques, Macaca Sylvanus. Anim. Behav. 86, 169-175.

Noë, R. 2001: Biological markets: partner choice as the driving force behind the evolution of cooperation. In: Economics in Nature: Social Dilemmas, Mate Choice and Biological Markets. (Noё, R., van Hooff, J. A. R. A. M., Hammerstein, P., eds). Cambridge University Press, Cambridge, pp. 93-118.

Noldus Information Technology 2003: MATMAN, Software for Matrix Manipulation and Analysis, Version 1.1. Noldus Information Technology, Wageningen, The Netherlands.

van Noordwijk, M. A. \& van Schaik, C. P. 2009: Intersexual food transfer among orangutans: do females test males for coercive tendency? Behav. Ecol. Sociobiol. 63, $883-890$.

Pastor-Nieto, R. 2001: Grooming, kinship and co-feeding in captive spider monkeys (Ateles geoffroyi). Zoo Biol. 20, 293-303.

Pelé, M., Thierry, B., Call, J. \& Dufour, V. 2010: Monkeys failed to reciprocate in an exchange task. Anim. Cogn. 13, 745-751.

Perry, S. 1996: Female-female social relationships in wild white-faced capuchin monkeys, Cebus capucinus. Am. J. Primatol. 40, 167-182.

Perry, S. \& Rose, L. 1994: Begging and transfer of coati meat by white-faced capuchin monkeys, Cebus capucinus. Primates 35, 409-415.

Pinheiro, J. C. \& Bates, D. M. 2000: Mixed Effects Models in S and S-PLUS, 1st edn. Springer-Verlag, New York.

Roberts, G. \& Sherratt, T. N. 1998: Development of cooperative relationships through increasing investment. Nature 394, 175-179.

Sabbatini, G., De Bortoli Vizioli, A., Visalberghi, E. \& Schino, G. 2012: Food transfers in capuchin monkeys: an experiment on partner choice. Biol. Lett. 8, 757759.
Sapolsky, R. M., Alberts, S. C. \& Altmann, J. 1997: Hypercortisolism associated with social subordinate or social isolation among wild baboons. Arch. Gen. Psychiatry 54, 1137-1143.

Schino, G. 2007: Grooming and agonistic support: a metaanalysis of primate reciprocal altruism. Behav. Ecol. 18, $115-120$.

Schino, G. \& Aureli, F. 2008: Grooming reciprocation among female primates: a meta-analysis. Biol. Lett. 4, 9 -11 .

Schino, G. \& Aureli, F. 2009: Reciprocal altruism in primates: partner choice, cognition, and emotions. Adv. Study Behav. 39, 45-69.

Schino, G. \& Aureli, F. 2010: Primate reciprocity and its cognitive requirements. Evol. Anthropol. 19, 130-135.

Schino, G. \& Pellegrini, B. 2009: Grooming in mandrills and the time frame of reciprocal partner choice. Am. J. Primatol. 71, 884-888.

Schino, G., Ventura, R. \& Troisi, A. 2005: Grooming and aggression in captive Japanese macaques. Primates 46, 207-209.

Schino, G., di Sorrentino, E. P. \& Tiddi, B. 2007: Grooming and coalitions in Japanese macaques (Macaca fuscata): partner choice and the time frame of reciprocation. J. Comp. Psychol. 121, 181-188.

Schino, G., Di Giuseppe, F. \& Visalberghi, E. 2009: The time frame of partner choice in the grooming reciprocation of Cebus apella. Ethology 115, 70-76.

Silk, J. B. 1982: Altruism among female Macaca radiata: explanations and analysis of patterns of grooming and coalition formation. Behaviour 79, 162-188.

Silk, J. B. 2002: Using the ' $F$ ' word in primatology. Behaviour 139, 421-446.

Silk, J. B. 2003: Cooperation without counting: the puzzle of friendship. In: The Genetic and Cultural Evolution of Cooperation. (Hammerstein, P., ed). The MIT Press, Cambridge, pp. 37-54.

Silk, J. B., Alberts, S. C. \& Altmann, J. 2003: Social bonds of female baboons enhance infant survival. Science $\mathbf{3 0 2}$, $1231-1234$.

Slocombe, K. E. \& Newton-Fisher, N. E. 2005: Fruit sharing between wild adult chimpanzees (Pan troglodytes schweinfurthii): a socially significant event? Am. J. Primatol. 65, 385-391.

StataCorp 2011: Stata Statistical Software: Release 12. StataCorp LP, College Station, Texas.

Stevens, J. R. 2004: The selfish nature of generosity: harassment and food sharing in primates. Proc. R. Soc. Lond. B 271, 451-456.

Tan, J. \& Hare, B. 2013: Bonobos share with strangers. PLOS ONE 8, e 51922.

Tiddi, B., Aureli, F., di Sorrentino, E. P., Janson, C. H. \& Schino, G. 2011 : Grooming for tolerance? Two mechanisms of exchange in wild tufted capuchin monkeys. Behav. Ecol. 22, 663-669. 
Troisi, A., Schino, G. \& Aureli, F. 1989: Allogrooming and interindividual proximity in two species of macaques (Macaca fascicularis and M. nemestrina). Behaviour 111, 196-206.

Tutin, C. E. G. 1979: Mating patterns and reproductive strategies in a community of wild chimpanzees (Pan troglodytes schweinfurthii). Behav. Ecol. Sociobiol. 6, 29-38.

Ventura, R., Majolo, B., Koyama, N., Hardie, S. \& Schino, G. 2006: Reciprocation and interchange in wild Japanese macaques: grooming, cofeeding, and agonistic support. Am. J. Primatol. 68, 1138-1149.

de Vries, H., Netto, W. J. \& Hanegraaf, P. L. H. 1993: MatMan: a program for the analysis of sociometric matrices and behavioural transition matrices. Behaviour 125 , $157-175$.

de Waal, F. B. M. 1989: Food sharing and reciprocal obligations among chimpanzees. J. Hum. Evol. 18, 433 - 459.

de Waal, F. B. M. 1997: The chimpanzee's service economy: food for grooming. Evol. Hum. Behav. 18, $375-386$.

de Waal, F. B. M. \& Suchak, M. 2010: Prosocial primates: selfish and unselfish motivations. Philos. Trans. R. Soc. Lond., B, Biol. Sci. 365, 2711-2722.
Watts, D. P. 2002: Reciprocity and interchange in the social relationships of wild male chimpanzees. Behaviour 139, 343-370.

White, F. J. \& Wrangham, R. W. 1988: Feeding competition and patch size in the chimpanzee species Pan paniscus and Pan troglodytes. Behaviour 105, 148-163.

Wobber, V., Hare, B., Maboto, J., Lipson, S., Wrangham, R. \& Ellison, P. T. 2010: Differential changes in steroid hormones before competition in bonobos and chimpanzees. Proc. Natl Acad. Sci. USA 107, 12457-12462.

Yamamoto, S. \& Tanaka, M. 2009: Do chimpanzees (Pan troglodytes) spontaneously take turns in a reciprocal cooperation task? J. Comp. Psychol. 123, 242-249.

\section{Supporting Information}

Additional supporting information may be found in the online version of this article:

Appendix S1. Supplementary results. 